\title{
Can we do without livestock?
}

\section{Wilhelm Windisch ${ }^{1}$}

Published online: 11 August 2021

(c) The Author(s) 2021
Global food security is running into severe problems. Half a billion individuals face acute hunger, and another two billion are exposed to undersupply with limiting essential nutrients. Food of animal origin is rich in such nutrients and even small daily intakes might help to resolve this so-called hidden hunger. On the other hand, livestock production is accused of contributing massively to environmental emissions and global warming. Furthermore, the global availability of agricultural area per individual is dramatically shrinking because of the ongoing rise in the human population, coupled with further losses of agricultural area because of, for example, erosion, desertification, and urban development. In 30 years from now, an average of $1500 \mathrm{~m}^{2}$ per individual must provide the complete food demand for one year. Current practices for channeling significant amounts of edible biomass into the feeding of livestock do not seem to be practicable long term.

Without doubt, the top priority in feeding the world is to generate plant-based biomass that is directly edible for humans as, at present, only a small part of harvested biomass ends up as edible food. Three quarters of global agricultural areas consist of permanent grasslands that cannot be used as arable land for mainly topographical and climatic reasons. These grasslands solely generate non-edible biomass. In addition, arable lands provide more non-edible than edible biomass. The maintenance of soil fertility requires crop rotation that includes non-edible plants. Furthermore, edible crop harvests entail both edible and non-edible biomass (co-products, e.g., straw) in similar quantities. Processing the harvested material, e.g., milling, extraction of oil, sugar and starch, and ethanol production, further generates large amounts of non-edible by-products. In central Europe, each kilogram of plant-based (vegan) food has been estimated to be associated with at least $4 \mathrm{~kg}$ of non-edible biomass from

Wilhelm Windisch

wilhelm.windisch@tum.de

1 Chair of Animal Nutrition, Technical University Munich (TUM), Liesel-Beckmann-Straße 2, 85354 Freising, Germany best-practice agriculture. Globally, the relative amounts of non-edible biomass are far higher.

Non-edible biomass harbors large amounts of plant nutrients (e.g., nitrogen, phosphorous). Returning these plant nutrients back into the soil is of the highest importance in order to maintain soil fertility and to run plant production in a sustainable way. One strategy is simply to leave the biomass on the fields. However, this is comparably inefficient, since the degradation of biomass and, hence, the release of plant nutrients occur asynchronously with regard to the nutritional needs of the plants. The second strategy is to utilize non-edible biomass for biogas production and to collect the residues that can be stored and applied as fertilizer when the plants actually need it. The third strategy is to feed it to livestock and, again later, to collect the dung until it can be applied to the soil. Both, biogas residues and livestock dung promote soil fertility to a much higher degree than the strategy of non-edible biomass being "left on the field". With regard to eco-production systems, biogas residues or livestock dung have recently been shown to double the harvest of edible crops per hectare and year compared with the first strategy when assessments are made of entire crop rotation periods. However, in contrast to biogas, livestock also generates high-quality human food. Consequently, no inherent antagonism exists between plant- vs. animal-based food. Both production lines are coupled synergistically in one common agricultural system.

Of course, the vital role of livestock relies on non-edible biomass that is inevitably produced within the agricultural systems. Under these conditions, no major difference is apparent in environmentally relevant emissions or other footprints, irrespective of whether the non-edible biomass rots on the fields, ends up in a biogas plant, or is fed to livestock. Consequently, livestock does not cause environmental burdens per se. However, as soon as arable land is rededicated to produce extra feed stuff for livestock, the subsequent generation of meat and other animal-derived products becomes fully responsible for the use of resources and for emissions into the environment. 
Non-edible biomass is rich in fiber. This restricts its use by highly efficient livestock such as chickens. The high productivity of chickens originates from their being fed with high-quality feed materials that are also suitable for human consumption. To a lesser extent, the same also applies to pigs. Ruminants, however, are less efficient in terms of feed input vs. food output, but they can be fed with low-quality fibrous, non-edible biomass. As a general rule, high feed efficiency and, vice versa, low footprints are coupled to a high degree of food competition with humans. In view of the severe shortage of available agricultural areas, livestock production cannot continue with excessive food competition. Ruminants will thus gain in relevance at the expense of pigs and, in particular, of poultry. The fallback to the inevitably produced non-edible biomass might severely limit the future volume of livestock production.

All efforts must be made to maximize the efficiency of utilizing non-edible biomass. Professional animal nutrition provides a range of means to support this goal, such as precise feeding and the inclusion of feed additives improving digestive capacity and gut health. Furthermore, available biomass must not be allowed to spoil (e.g., it needs to be properly preserved) and feed quality should be improved (e.g., plants have to be bred to avoid the presence of toxins, high lignin, etc.). Feed/food processing may further widen bottlenecks in the use of non-edible biomass. For example, lupin seeds may hardly be used as human food or animal feed because of the presence of toxic alkaloids. However, processing technology allows the separation of lupin seeds into protein isolates for the food industry, high-quality nonedible biomass for animal feed purposes, and a small portion of residuals containing the unwanted toxic components. This example shows that the overarching goal is to separate limited amounts of biomass into its various compartments and to utilize them according to the principles of a circular economy.

Alternatives to common livestock production seem to be becoming popular. Nevertheless, they should first be assessed as to whether the handling of edible and non-edible biomass matches the principles of a circular economy. For example, intensive aquaculture significantly reduced the dietary inclusion of fish meal. However, the gaps in feed formulation were closed with high-quality (edible for humans) feed materials from arable land, hence intensifying food competition with humans. In the case of insects, doubts remain as to whether current production systems will compete with ruminants in transforming fibrous (non-edible) biomass into human food. Artificial meat (cultured muscle cells) grows in culture media composed of highly purified nutrients (e.g., glucose, amino acids) which in turn are produced from already existing plant-based food (e.g., soybean, corn). Since muscle cells are living organisms running their own metabolism, the amount of harvested products is always smaller that the feed input via culture media. This demonstrates the general problem of any production system in which living organisms (from animals to bacteria) transform feed biomass through metabolic processes into human food. As soon as edible biomass is used, the systems cause a net loss of nutrients compared with the direct use of the feed input for human nutrition. A different picture applies for "vegan imitates" of animal-based food. Indeed, they are produced from existing, edible plant materials, and the product is used directly for human consumption. Furthermore, the production of the final food involves non-edible by-products that can be fed to livestock. Therefore, the production of vegan imitates and livestock nutrition is per se not antagonistic and can be coupled synergistically in one common system following the principles of a circular economy.

In summary, we cannot do without livestock at the present time. Livestock keeps agricultural biomass in circulation, serves as an essential link to the by-products from the food industry, and provides high-quality food in addition to existing plant-based food. Environmental damage through livestock production only occurs when it is run in excess. The future challenge is to balance the agricultural generation of plant-derived (vegan) food against that of animal-derived food based on closed nutrient cycles and the synergistic stimulation of the two production lines. Optimal utilization of non-edible biomass is key for this purpose (Windisch and Flachowsky 2020).

Funding Open Access funding enabled and organized by Projekt DEAL.

Open Access This article is licensed under a Creative Commons Attribution 4.0 International License, which permits use, sharing, adaptation, distribution and reproduction in any medium or format, as long as you give appropriate credit to the original author(s) and the source, provide a link to the Creative Commons licence, and indicate if changes were made. The images or other third party material in this article are included in the article's Creative Commons licence, unless indicated otherwise in a credit line to the material. If material is not included in the article's Creative Commons licence and your intended use is not permitted by statutory regulation or exceeds the permitted use, you will need to obtain permission directly from the copyright holder. To view a copy of this licence, visit http://creativecommons.org/licenses/by/4.0/.

\section{Reference}

Windisch W, Flachowsky G (2020) Tierbasierte Bioökonomie. In: Thrän D, Moesenfechtel U (eds) Das System Bioökonomie. Springer Nature, Berlin, pp 70-86 (ISBN 978-3-662-60730-5)

Publisher's Note Springer Nature remains neutral with regard to jurisdictional claims in published maps and institutional affiliations. 